André Guaragna

MARCONDES ${ }^{1}$

Maria de Lourdes $M$.

SHIKAMA ${ }^{2}$

Sílvio Arruda

VASCONCELLOS ${ }^{1}$

Nílson Roberti BENITES ${ }^{1}$

Zenaide Maria de MORAIS

Eliana $\mathrm{ROXO}^{3}$

Ricardo Augusto DIAS'

Sylvia Luisa Pincherle

Cardoso LEÃO ${ }^{4}$

Sônia Regina PINHEIRO ${ }^{1}$

Correspondência para:

SÔNIA REGINAPINHEIRO

Departamento de Medicina Veterinária

Preventiva e Saúde Animal

Faculdade de Medicina Veterinária e

Zootecnia

Universidade de São Paulo

Av. Prof. Orlando Marques de Paiva, 87.

Cidade Universitária Armando Salles

Oliveira

05508-270 - São Paulo-SP

soniapin@usp.br

Recebido para publicação: 23/06/04 Aprovado para publicação: 13/07/05

\section{Comparação entre a técnica de cultivo em camada delgada de ágar Middlebrook 7H11 e meio de Stonebrink para isolamento de Mycobacterium Bovis em amostras de campo}

\author{
1 - Deparamento de Medicina Veterinária Preventiva e Saúde Animal da \\ Faculdade de Medicina Veterinária e Zootecnia da Universidade de São \\ Paulo, São Paulo - SP \\ 2 - Instituto Adolfo Lutz - Laboratório Regional de Sorocaba, Sorocaba - SP \\ 3 - Instituto Biológico, São Paulo - SP \\ 4 - Universidade Federal de São Paulo, São Paulo - SP
}

\section{Resumo}

O presente trabalho teve por objetivo avaliar a eficiência da técnica de cultivo em camada delgada de ágar Middlebrook 7H11 (TL7H11) no isolamento de Mycobacterium bovis de lesões sugestivas de tuberculose em bovinos, comparando seus resultados com os métodos tradicionais de cultivo. Numa primeira fase foram utilizadas estirpes padrão de $M$. bovis AN5 e $M$. tuberculosis H37Rv mantidas em laboratório, para comparação de desempenho entre o cultivo em TL7H11 e nos meios de Stonebrik e Petragnani. Ambas estirpes apresentaram crescimento visível em TL7H11 no terceiro dia de cultivo enquanto que nos meios de Stonebrink e Petragnani só houve crescimento a partir do $14^{\circ}$ dia. Aos 13 dias de cultivo em TL7H11 foi possível diferenciar as duas estirpes pelas características morfológicas das colônias. Numa segunda fase, 62 amostras de campo foram cultivadas em TL7H11 e Stonebrink para isolamento de M. bovis. As amostras isoladas foram detectadas pelo TL7H11 até os 21 dias de cultivo contra nenhum crescimento dos tubos de Stonebrink. O tempo médio de crescimento no TL7H11 foi de 19,0 dias contra 49,0 dias do meio de Stonebrink $(p=0,014)$.

\section{Introdução}

A tuberculose é a principal causa de morte provocada por um único agente em todo o mundo'. O Mycobacterium tuberculosis é a causa mais comum de tuberculose humana, mas há uma proporção desconhecida de casos provocados pelo $M$. .bovis, principal responsável pela doença em bovinos. Nos países industrializados os programas de controle e erradicação da tuberculose animal, juntamente com a pasteurização do leite, diminuíram drasticamente a incidência da doença causada pelo $M$.bovis em humanos e bovinos ${ }^{2}$. Mesmo assim, em alguns países o bacilo bovino tem sido diagnosticado como agente causador da envolvido ${ }^{4,5,6}$.
Palavras-chave:

Mycobacterium bovis. Meios de cultura. Bacteriologia veterinária. Middlebrook $7 \mathrm{H} 11$. tuberculose em 1 a $6 \%$ dos casos totais em humanos tanto na forma pulmonar como nas extrapulmonares, assumindo caráter de doença profissional em $64 \%$ dos casos $^{3} . \mathrm{Na}$ tuberculose bovina estima-se que a perda do potencial produtivo dos animais infectados seja de 10 a $25 \%$, além da condenação das carcaças nos abatedouros e da perda de mercados para exportação por razões sanitárias. A implementação de planos de combate e erradicação da tuberculose (principalmente nos países em desenvolvimento) passa por estratégias de diagnóstico dos animais infectados e abate dos mesmos, com o isolamento e identificação do agente 
$\mathrm{O}$ isolamento das microbactérias pode ser rotineiramente realizado pela sua inoculação em meios de cultura sólidos. Os mais recomendáveis são os meios de Löwenstein Jensen, Petragnani e Middlebrook $7 \mathrm{H} 10$ e $7 \mathrm{H} 11$ para $M$. tuberculosis, enquanto que Stonebrink é o único meio utilizado para isolamento de $M$. bovis $^{7}$. O M. bovis tem dificuldade em se desenvolver em meios glicerinados, e por este motivo se desenvolve melhor no meio de Stonebrink, onde o glicerol é substituído pelo piruvato de sódio. Para o isolamento primário do $M$. bovis nos meios à base de ágar, recomenda-se uma pequena concentração de $\mathrm{CO}_{2}$ (não superior a 5\%), já que o $M$. bovis é microaerófilo?.

O isolamento de $M$. tuberculosis nos meios de Löwenstein-Jensen e Petragnani leva de 12 a 25 dias enquanto que o $M$. bovis leva de 24 a 40 dias para se desenvolver no meio de Stonebrink, dificultando o diagnóstico da doença.

O uso de modernas técnicas radiométricas e métodos envolvendo engenharia molecular como a reação em cadeia da polimerase (PCR) tem reduzido substancialmente o tempo necessário para o diagnóstico de TB, mas seu alto custo torna essas técnicas inviáveis para muitos laboratórios em países em desenvolvimento ${ }^{12}$. Além disso, partem do princípio de que já se tem um isolado de Mycobacterium, sugerindo que o fator limitante para a agilidade destes métodos seja a rapidez no isolamento $8,9,10,11$.

Runyon foi o primeiro a descrever o uso de meios transparentes à base de ágar para a identificação precoce de amostras clínicas de micobactérias ${ }^{12}$. É um método rápido e que tem sido proposto recentemente como uma alternativa de baixo custo no diagnóstico e cultivo de micobactérias ${ }^{7,13,14}$.

Este trabalho comparou o desempenho do meio TL7H11 para o isolamento de Mycobacterium bovis a partir de amostras provenientes de lesões de animais com suspeita de tuberculose com os métodos tradicionais de cultivo.

\section{Materiais e Métodos}

Este trabalho foi desenvolvido em duas fases. $\mathrm{Na}$ primeira, 200 placas com 5 $\mathrm{ml}$ de TL7H11 e 200 tubos com $5 \mathrm{ml}$ de meio de Stonebrink foram semeados com suspensão bacteriana de $M$. bovis estirpe AN5 e 200 placas com $5 \mathrm{ml}$ de TL7H11 e 200 tubos com $5 \mathrm{ml}$ de meio de Petragnani foram semeados com suspensão bacteriana de M. tuberculosis estirpe H37Rv. Os tubos de Petragnani foram incubados a $37 \mathrm{oC}$ em estufa bacteriológica comum enquanto os tubos de Stonebrink, que foram fechados com rolha de cortiça, tiveram a rolha queimada para gerar ambiente de microaerofilia para então serem incubados a $37 \mathrm{oC}$ em estufa bacteriológica comum. As placas foram incubadas a $37 \mathrm{oC}$ em jarra de microaerofilia $\left(5-10 \% \mathrm{CO}_{2}\right)$. Os tubos de Petragnani e Stonebrink foram observados uma vez por semana por 3 semanas enquanto as placas foram observadas nos dias 3, 5 e 7 pós-semeadura com auxílio de um microscópio óptico comum (aumento de 40 e 100 x). As suspensões de $M$. bovis AN5 e $M$. tuberculosis $\mathrm{H} 37 \mathrm{Rv}$ foram preparadas imediatamente antes da semeadura, com a diluição 1:100 de uma suspensão de 0,06 gr de bacilos em $100 \mathrm{~mL}$ de salina estéril com $0,05 \%$ de Tween 80.

$\mathrm{Na}$ segunda fase, 62 amostras de lesões suspeitas de tuberculose provenientes de bovinos de abatedouros foram descontaminadas pelo método de Petroff e cada uma foi incubada em 2 tubos de Stonebrink e 5 placas de TL7H11 com 0,445 $\mathrm{g} / \mathrm{L}$ de piruvato de sódio. Os tubos foram incubados a 37 oC em estufa bacteriológica comum nas condições de microaerofilia descritas anteriomente e as placas foram incubadas a $37 \mathrm{oC}$ em jarra de microaerofilia $\left(5-10 \% \mathrm{CO}_{2}\right)$. A leitura dos tubos foi feita semanalmente por 8 semanas enquanto as placas foram observadas duas vezes por semana por 4 semanas com microscópio óptico comum (aumento de 40 e 100x). Todos os procedimentos da primeira e da 
segunda fase foram feitos em cabine de fluxo laminar. As leituras das placas de TL7H11 foram feitas em microscópio fora do fluxo laminar, sendo que as placas foram seladas com fita adesiva (Micropore â) para evitar a formação de aerossóis.

Os meios de Stonebrink e de Petragnani foram preparados conforme as recomendações do Centro Panamericano de Zoonosis ${ }^{15}$ e as placas de TL7H11 segundo as recomendações da Universidad de Las Naciones Unida ${ }^{16}$. Para favorecer $\mathrm{O}$ isolamento das cepas de campo na segunda fase do trabalho, substituiu-se o glicerol por 0,445 g/L de piruvato de sódio.

Todas as colônias bacterianas isoladas foram coradas pelo método de Ziehl Nielsen e as cepas isoladas foram identificadas pelo método de PRA (PCR - Restricition Enzyme Analysis). As colônias que não apresentaram característica de BAAR, foram consideradas contaminações.

Nas comparações entre os dias de crescimento dos $M$ bovis e $M$. tuberculosis nos meios TL7H11 e Stonebrink e Petragnani foram realizados com o teste Fisher ${ }^{7}$. Quando se comparou os dias de crescimento do M. bovis nos meios TL7H11 e Stonebrink na segunda fase utilizou-se o test t pareado ${ }^{17}$.

\section{Resultados}

Os resultados da primeira fase mostraram que $100 \%$ das placas TL7H11 semeadas com $M$. bovis AN5 tiveram crescimento já no $3^{\circ}$ dia de cultivo enquanto que $75,5 \%$ dos tubos de Stonebrink apresentaram crescimento somente a partir do $14^{\circ}$ dia e $100 \%$ dos tubos aos 21 dias (Tabela 1). Verificou-se que não houve diferença estatística significante $(\mathrm{P}<0,05)$ quando se comparou o crescimento no $3^{\circ}$ dia no meio de TL7H11 com o crescimento ao $14^{\circ}$ dia no meio de Stonebrink.

As placas de TL7H11 semeadas com M. tuberculosis $\mathrm{H} 37 \mathrm{Rv}$ apresentaram crescimento de $2 \%$ no $3^{\circ}$ dia de cultivo, $87,5 \%$ no $5^{\circ}$ dia e $97 \%$ no $7^{\circ}$ dia enquanto que somente no $14^{\circ}$ dia $78,5 \%$ dos tubos apresentaram crescimento, aumentando para $100 \%$ no $21^{\circ}$ dia (Tabela 1). Verificou-se que houve diferença estatisticamente significante com maior freqüência de isolamento $(\mathrm{P}<0,05)$ entre o meio de Petragnani a partir do $14^{\circ}$ dia quando comparado com o sétimo dia no meio TL7H11.

Verificou-se também que as freqüências de isolamento de cepas de $M$. bovis tanto no terceiro, quanto no quinto, bem como no sétimo dia foram maiores estatisticamente $(\mathrm{P}<0,05)$ do que do $M$. tuberculosis no meio TL7H11.

As figuras 1 e 2 mostram colônias de M. bovis e $M$. tuberculosis com 13 dias de cultivo onde pode-se observar a formação de fator corda.

Na segunda fase, $12,9 \%$ das amostras apresentaram crescimento positivos no meio de TL7H11 e 14,5\% apresentaram crescimento positivo no meio de Stonebrink, sendo que esta diferença não foi estatisticamente significante $(\mathrm{P}<0,05)$. Das 12 amostras isoladas apenas seis serviram como comparação por terem crescidos em ambos os meios.

A taxa de contaminação total nesta fase para o TL7H11 foi de $21,0 \%$ enquanto que para os tubos foi de $4,8 \%$, resultado este que demonstra que a frequência de contaminação no meio TL7H11 foi maior estatisticamente $(\mathrm{P}<0,05)$ do que a freqüência de contaminação no meio de Stonebrink.

Mais de 75\% das amostras positivas foram detectadas pelo TL7H11 até os 21 dias de cultivo contra $0 \%$ dos tubos (Figura 3). O tempo médio para detecção das primeiras UFCO foi de 19,0 dias (DP $\pm 2,2)$ para o TL7H11 contra 49, 0 dias (DP $\pm 5,7)$ dos tubos com Stonebrink, sendo esta diferença confirmada pelo teste estatístico do teste $\mathrm{t}$ pareado $(p=0,0001)$. Em algumas amostras as UFCO de $M$. bovis já eram visíveis aos 20 dias de cultivo no meio TL7H11 (Figura 4).

Todas as micobactérias isoladas nesta fase foram identificadas pelo método de PRA (PCR - Restriction Enzyme Analysis) como sendo pertencentes ao complexo $M$. tuberculosis. 
Tabela 1 - Número de amostras positivas e porcentagens das placas e dos tubos para as estirpes de laboratório M. bovis AN5 e M. tuberculosis H37Rv obtidas na primeira fase do trabalho. São Paulo, 2004

\begin{tabular}{|c|c|c|c|c|c|c|c|c|c|c|c|c|c|c|}
\hline \multirow{4}{*}{$\begin{array}{l}\text { Suspensão } \\
\text { bacteriana }\end{array}$} & \multirow{4}{*}{ Total } & \multicolumn{6}{|c|}{ Placas positivas / total } & \multirow{4}{*}{ Total } & \multirow{2}{*}{\multicolumn{6}{|c|}{$\frac{\text { Tubos positivos / total }}{\text { dias pós-semeadura }}$}} \\
\hline & & \multicolumn{6}{|c|}{ dias pós-semeadura } & & & & & & & \\
\hline & & \multicolumn{2}{|c|}{3} & \multicolumn{2}{|c|}{5} & \multicolumn{2}{|c|}{7} & & \multicolumn{2}{|c|}{7} & \multicolumn{2}{|c|}{14} & \multicolumn{2}{|c|}{21} \\
\hline & & $\mathrm{n}$ & $\%$ & $\mathrm{n}$ & $\%$ & $\mathrm{n}$ & $\%$ & & $n$ & $\%$ & $\mathrm{n}$ & $\%$ & $\mathrm{n}$ & $\%$ \\
\hline M. bovis & 200 & $200^{d}$ & $100^{\mathrm{a}}$ & $200^{d}$ & 100 & $200^{d}$ & 100 & 200 & 0 & 0 & 151 & $75,5^{\mathrm{a}}$ & 200 & 100 \\
\hline M. tuberculosis & 200 & $4^{\mathrm{d}}$ & 2 & $175^{\mathrm{d}}$ & $87,5^{\mathrm{b}}$ & $194^{\mathrm{d}}$ & $97^{\mathrm{b}}$ & 200 & 0 & 0 & 157 & 78,5 & $200^{c}$ & 100 \\
\hline
\end{tabular}

$\mathrm{a}=$ não houve diferença estatística significante $(\mathrm{P}<0,05)$ quando se comparou o crescimento no $3^{\circ}$ dia no meio de TL7H11 com o crescimento ao $14^{\circ}$ dia no meio de Stonebrink.

$\mathrm{b}=$ diferença estatística significante $(\mathrm{P}<0.05)$ da freqüência de isolamento de $M$. tuberculosis no meio TL7H11 no quinto e sétimo dias de cultivo quando comparado com cultivo em tubos após 7 e 14 dias de cultivo.

$\mathrm{C}=$ diferença estatística significante $(\mathrm{P}<0.05)$ da freqüência de isolamento de $M$. tuberculosis após 21 dias de cultivo em tubos quando comparado com o sétimo dias de cultivo no meio TL7H11.

$\mathrm{d}=$ diferença estatisticamente significante $(\mathrm{P}<0.05)$ de freqüência de isolamento de $M$. bovis no $3^{\circ}, 5^{\circ}$ e $7^{\circ}$ dia maior que $M$. tuberculosis em TL7H11.

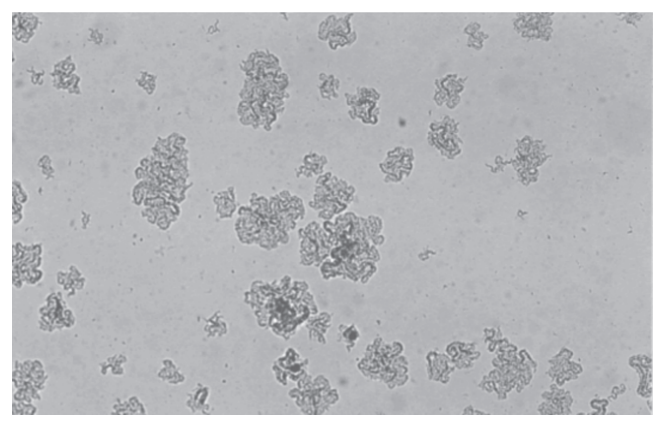

Figura 1 - Microcolônias de M. bovis estirpe AN5 com 13 dias de cultivo com formação característica de fator corda. Aumento de $100 x$

\section{Discussão}

As estirpes de M. bovis AN5 e M. tuberculosis $\mathrm{H} 37 \mathrm{Rv}$ revelaram crescimento significativamente mais rápido nas placas com meio TL7H11 do que nos tubos com meios tradicionais e ambos mais rápidos do que colônias provenientes de primoisolamento. Este fato pode ser explicado pela adaptação dessas estirpes aos meios de cultura em virtude dos sucessivos repiques para sua manutenção no laboratório. De fato, estirpes mantidas por longos períodos em meios de cultura podem apresentar comportamento diverso do existente em condições naturais quando provenientes de animais doentes $12,19,20$. Neste trabalho, a identificação presuntiva de $M$. bovis AN5 e M. tuberculosis $\mathrm{H} 37 \mathrm{Rv}$ foi possível pela a

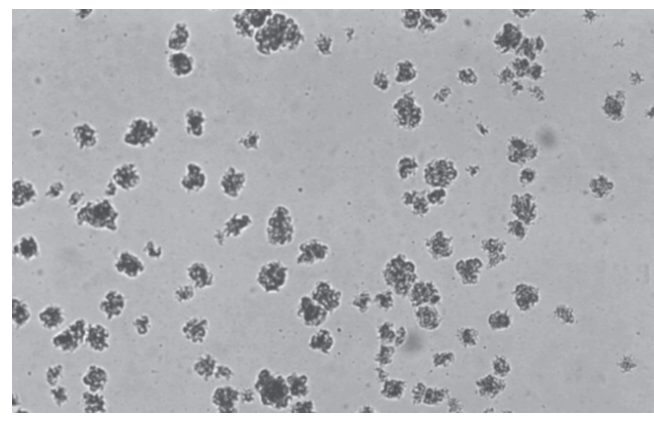

Figura 2 - Microcolônias de M. tuberculosis estirpe H37Rv com 13 dias de cultivo com formação característica de fator corda. Aumento de 100x

observação de fator corda logo no início do crescimento, enquanto que diferenças morfológicas entre as duas estirpes foi possível aos 13 dias de cultivo.

Embora o M. bovis AN5 tenha se desenvolvido muito bem no meio de Middlebrook 7H11 tendo glicerol como fonte de carbono, testes preliminares mostraram que as micobactérias isoladas a partir de amostras de campo (bovinos com suspeita de tuberculose) não se desenvolviam nesse meio. Este fato pode ser explicado pela tolerância do M. bovis AN5 ao glicerol enquanto que a maioria das amostras isoladas de bovinos são inibidas na presença deste ingrediente ${ }^{21,22}$, sendo necessária a sua substituição pelo piruvato de sódio como fonte de carbono para a segunda fase.

Quando se trabalhou com amostras 


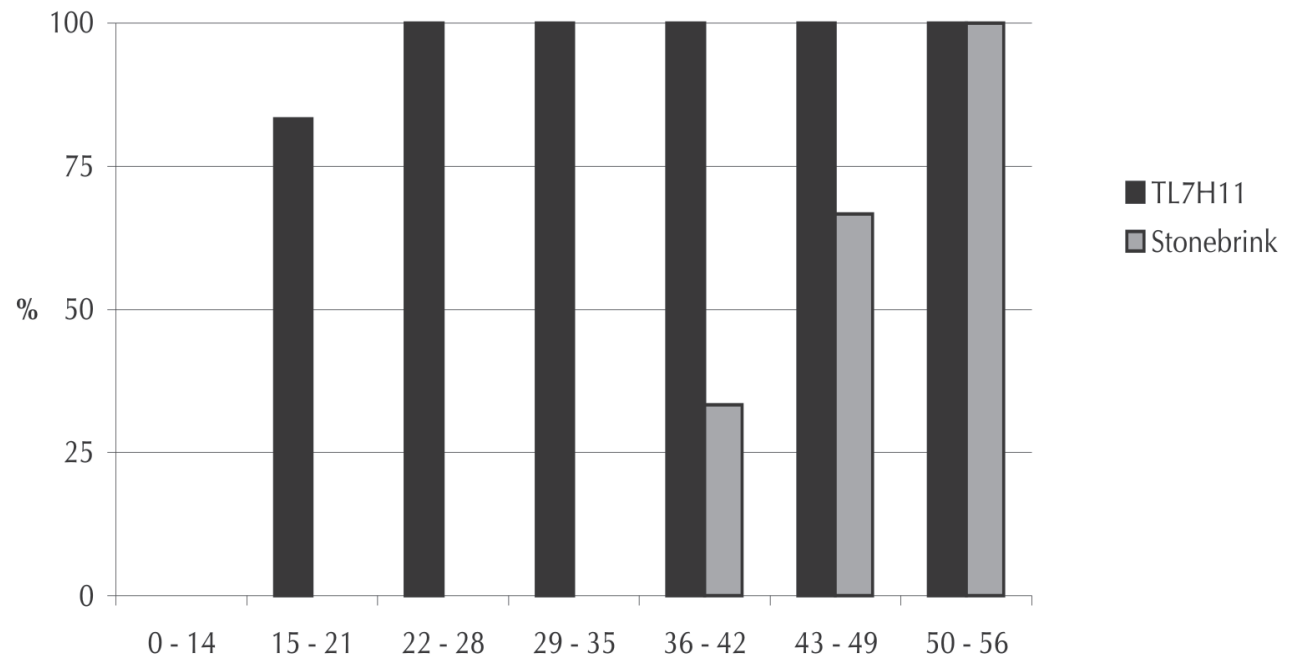

Tempo de detecção em dias

Figura 3 - Porcentagens acumuladas de resultados positivos de M. bovis de acordo com o tempo de crescimento em meio de Stonebrinke TL7H11

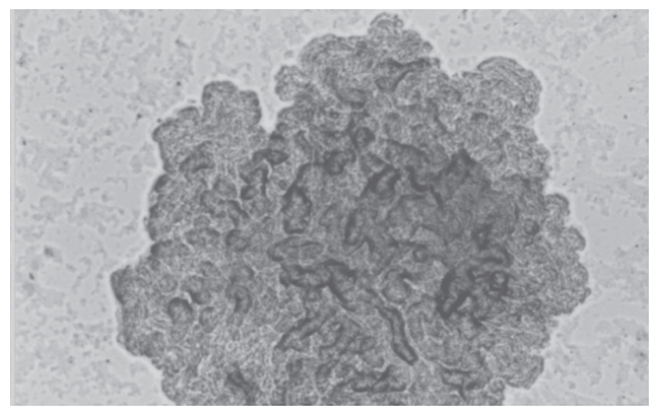

Figura 4-Microcolônia de M. bovis com 20 dias de cultivo proveniente de material de campo. Observar a formação característica de fator corda. Aumento de $100 x$

de campo (segunda fase), $83,3 \%$ das amostras positivas foram detectadas pelo TL7H11 até os 21 dias de cultivo contra $0 \%$ dos tubos, sendo o tempo médio de detecção de 19,0 dias (DP $\pm 2,2)$ para o TL7H11 contra 49,0 dias (DP $\pm 5,7)$ dos tubos (figura 3). Apesar do período de tempo de isolamento na segunda fase ter sido maior do que na primeira fase no meio TL7H11, o período verificado na segunda fase ainda é muito inferior ao observado pela técnica tradicional o que representa uma nítida vantagem da técnica estudada, sendo que este período é o principal fator limitante para o diagnóstico da tuberculose bovina pelo cultivo microbiano.

As colônias isoladas a partir de material de campo demonstraram a presença do fator corda (figura 4), se assemelhando mais às colônias de $M$. bovis estirpe AN5 do que às $M$. tuberculosis $\mathrm{H} 37 \mathrm{Rv}$, sugerindo a possibilidade de identificação precoce das micobactérias com base em suas características morfológicas. Runyon 18 e outros autores ${ }^{13,14,23,24}$ já haviam descrito essa possibilidade como uma vantagem do cultivo em TL7H11 na identificação e classificação precoce de micobactérias. Metchock e Diem ${ }^{25}$ ainda sugerem que as observações de microcolônias em TL7H11 podem servir como guia para a escolha da sonda genética a ser utilizada. Todas as micobactérias isoladas neste experimento foram identificadas pelo método de PRA (PCR Restricition Enzyme Analysis) como sendo 
pertencentes ao complexo $M$. tuberculosis.

A taxa de contaminação observada em TL7H11 quando comparada com o Stonebrink no presente trabalho $(21,0 \%$ e $4,8 \%$ dos tubos) reflete a principal limitação desta técnica, já que o meio de Middlebrook 7H11 é bastante rico e possui dez vezes menos verde de malaquita que os meios tradicionais. Assim, a escolha do método de descontaminação da amostra é muito importante, pois métodos muito agressivos podem danificar as micobactérias tornando seu crescimento muito lento e difícil. Entretanto, métodos cuja potência da solução descontaminante seja reduzida favorecem o isolamento de micobactérias, mas podem permitir o crescimento de contaminantes, indicando o uso de antibióticos e antimicóticos ${ }^{7,13,14,16}$. Mejia et al. ${ }^{13}$ ao trabalhar com diferentes tipos de amostras provenientes de pacientes humanos, obtiveram 16,5\% de contaminação mesmo utilizando os antibióticos piperacilina, anfotericina $\mathrm{B}$ e trimetropin para inibir as contaminações. A impossibilidade de se estabelecer um protocolo ou treinamento adequado para a colheita, acondicionamento e transporte do material recebido para a segunda fase propiciou grande variação na qualidade das amostras, indicando a escolha de um método agressivo para descontaminação (Petroff), o que poderia explicar o baixo índice de isolamentos (19,4\%). Assim, das 12 amostras isoladas apenas seis serviram como comparação por terem crescidos em ambos os meios.

$\mathrm{O}$ isolamento de micobactérias em geral parece ser favorecido por atmosfera com
3 a $11 \%$ de $\mathrm{CO}_{2}$ durante os primeiros 7 a 10 dias quando então entram em fase logarítmica de crescimento, diminuindo a sua dependência de $\mathrm{CO}_{2}$. Entretanto, a microaerofilia é obrigatória por todo o período de incubação em TL7H11, qualquer que seja a espécie envolvida ${ }^{7}$. Assim, optou-se por manter as placas de TL7H11 em ambas as fases do trabalho sob incubação em microaerofilia enquanto que os tubos com Stonebrink tiveram a rolha de cortiça queimada para gerar uma tensão de $\mathrm{CO}_{2}$ no interior do tubo.

Além da precocidade do cultivo de $M$. bovis em TL7H11 verifica-se também a simplicidade requerida para o trabalho dispensando microscópios especiais ou qualquer outro aparato técnico sofisticado podendo ser usada em qualquer laboratório. Idigoras et al. ${ }^{24}$ observaram que o aprendizado dos técnicos para a leitura nas placas costuma ser rápido e passa a ter boa confiabilidade quando eles aprendem a distinguir os diferentes tipos de colônias de artefatos que podem aparecer nas placas (debris celulares, contaminações), tornando a leitura um processo rápido e seguro.

A freqüência de isolamento de $M$. bovis no meio de TL7H11 bem como a velocidade de crescimento bacteriano neste meio quando comparado com a técnica tradicional, demonstra uma grande vantagem da utilização do meio de TL7H11 no isolamento do M. bovis. Entretanto, novos estudos devem ser feitos com a adição de antibióticos ao meio de TL7H11 e outros métodos de descontaminação para as amostras a fim de se diminuir a contaminação das placas.

Microcolony detection of Mycobacterium Bovis in Middlebrook 7H11 thin layer culture

\section{Abstract}

The aim of this article is to evaluate the efficiency of the cultivation technique in thin layer of Middlebrook 7H11 (TL7H11) for isolating Mycobactererium bovis from suggestive lesions of tuberculosis in cattle and to compare the results with traditional methods of cultivation. At the first step it was used M. bovis AN5 and M. tubercuolosis H37Rv standard strain. The both performance were compared between the cultivation in TL7H11 and in the Stonebrink and Petragnani media. The strains presented visible growing in TL7H11 at the third day of
Key-words:

Mycobacterium bovis.

Cultivation media. Veterinary bacteriology. Middlebrook $7 \mathrm{H} 11$. 
cultivation, while the Stonebrink and Petragnani there were growing just at the 14 day. At the 13 day of cultivation it was possible to differentiate both strains by their colony morphological characteristics. The second step was to cultivate 62 clinicals samples in TL7H11 and Stonebrink for tentative isolation of $M$. bovis. The isolated samples were detected in TL7H11 until 21 days of cultivation whereas none samples weregrown in Stonebrink tubes. The median time of growing in TL7H11 was 19,0 days against 49,0 days of Stonebrink ( $\mathrm{p}=0,014)$.

\section{Referências}

1 WHO - WORLD HEALTH ORGANIZATION. Zoonotic tuberculosis (Mycobacterium bovis): memorandum from a WHO meeting with the participation of FAO. Bull. World Health Organ., v. 72, p. 851-857, 1994.

2 COSIVI O.; et al. Zoonotic tuberculosis due to Mycobacterium bovis in developing countries. Emerging Infectious Diseases, v. 4, n. 1,1998.

3 LATINI, M. S.; LATINI, et al. Bovine Tuberculosis in Latin América and Caribbean: current status, control and erradication programs. Vet. Microbiology, v. 40, n. 1-2, p. 5-14, 1994.

4 NADER, A.; HUSBERG, H. Estimación de perdidas de producción por tuberculosis bovina en un rodeo lechero. Rev. Med. Vet., v. 68, n. 36-39, 1988.

5 OFFICE ITERNATIONAL DES EPIZOOTIES. Manual of Standards for diagnostic tests and vaccines. Paris: OIE, 1992.

6 BAWINEK F.; TAYLOR N. M. Assesment of the socioeconomic importance of Bovine Tuberculosis in Turkey and possible strategies for control or eradication. Turkish-German Animal Health Information Project. General Directore of Protection and Control, Ankara: a h i p, 1996.

7 KONEMAN, E. W. Micobactérias. In: KONEMAN, E. W.; ALLEN, S. D.; JONDA, W. M.; SCHRECKENBERGER， P. C. Diagnóstico microbiológico - texto e atlas colorido. Washington: C. Winn Jr., 2001, p.903-954.

8 NORDEN, M. A.; et al. Rapid susceptibility testing of Mycobacterium tuberculosis (H37Rv) by flow cytometry. J. Clin. Microbiol. v. 33, p. 1231 1237,1995

9 YAJKO, D. M.; WAGNER, C.; TEVERE, V. J.; KOCAGOZ, T.; HADLEY, W. K.; CHAMBERS, H. F. Quantitative culture of Mycobacterium tuberculosis from clinical sputum specimens and dilution endpoint of its detection by the Amplicor PCR assay. J. Clin. Microbiol., v. 33, p. 1944-1947, 1995.

10 WALTERS, S. B.; HANNA, B. A. Testing of susceptibility of Mycobacterium tuberculosis to isoniazid and rifampin by mycobacterium growth indicator tube method. J. Clin. Microbiol, v. 34, p.
1565-1567, 1996.

11 PALOMINO, J. C.; PORTAELS, F. Effects of Decontamination Methods and Culture Conditions on Viability of Mycobacterium ulcerans in the BACTEC System. J. Clin. Microbiol. v. 36, p. 402-408, 1999.

12 RUNYON, E. H. Identification of mycobacterial pathogens utilizing colony characteristics. American Journal of Clinical Pathology, v. 54, p. 578-586, 1970.

14 SMITH, W. L.; MCGARVEY, K. L.; CULLOR, J. S. The use of spiral plating and microscopic colony counting for the rapid quantitation of Mycobacterium paratuberculosis. The Society for Applied Microbiology, Letters in Applied Microbiology, v.36, p. 293-296, 2003.

15 CENTRO PANAMERICANO DE ZOONOSIS. Bacteriologia de la tuberculosis humana y animal. Buenos Aires: Organización Panamericana de la Salud, 1988, 63 p. (Serie de Monografias Científicas y Técnicas; 11 rev. 1).

16 UNIVERSIDADE DE LAS NACIONES UNIDAS. Nuevas tecnologias para el diagnóstico y pruebas de susceptibilidad a drogas de M. Tuberculosis para países en vias de desarollo. In: PROGRAMA DE BIOTECNOLOGIA PARA LATINOAMÉRICA Y EL CARIBE - BIOLAC; Red Latinoamericana y del Caribe de tuberculosis - RELACTB,1998, La Paz, Bolivia. Curso ...

17 GRAPHPAD INSTAT SOFTWARE. Statistical analysis systems for personal computers. 1990-1993.

18 WHITMORE, E. J.; MINER, N. A. Analysis and optimization of a quantitative organic soil neutralization test for desinfectants. Journal of the AOAC., v. 59, n. 6, p. 1344-1351, 1976.

19 ALLEN, B. W. Storage of mycobacteria at $-20^{\circ} \mathrm{C}$. Med. Lab. Sci., n. 43, p. 390-392, 1986.

20 LIND, A.; et al. A carrier method for the assessment of the effectiveness of disinfectants against Mycobacterium tuberculosis. J. Hosp. Infec., n. 7, p. 60-67, 1986.

13 MEJIA, G. I.; et al. Microcolony detection in $7 \mathrm{H} 11$ thin layer culture is na alternative for rapid diagnosis of Mycobacterium tuberculosis infection. Int. Tuberc. Lung Disease, Colombia, v. 3, n. 2, p. 138-142, 1999.

21 ANERIK A. I. Estudio experimental sobre el 
diagnóstico de la tuberculosis bovina mediante pruebas de cultivo e inoculación animal. Cienc. Vet., Maracaibo, v. 4, p. 137-200, 1974.

22 CORNER, L. A.; NICOLACOPOULOS, C. Comparison of media used for the primary isolation of Mycobacterium bovis by veterinary and medical diagnostic laboratories. Australian Veterinary Journal, v. 65, n. 7, p. 202-204, July, 1988.

23 WELCH, D. F.; GURUSWAMY, A. P.; SIDES, S. J.; SHAW, C. H.; GILCHRIST, M. J. Timely culture for mycobacteria which utilizes a microcolony method. Journal Clin. Microbiology, v. 31, n. 8, p. 2178-2184, 1993.

24 IDIGORAS. P.; et al. Rapid Detection of Tuberculous and Non-Tuberculous Mycobacteria by Microscopic Observation of Growth on Middlebrook 7H11 Agar. Eur. J. Clin. Microbiol. Infect. Dis. Spain, v. 14, n. 1, p. 6-10, 1995.

25 METCHOCK, B.; DIEM, L. Algorithm for use of nucleic acid probes for identifying Mycobacterium tuberculosis from BACTEC 12B bottles. J. Clin. Microbiol. , v. 33, p. 1934-1937, 1995. 